\title{
HIA Antigens in Inflammatory Bowel Disease
}

\author{
Nobuo Hiwatashi, Takao Kikuchi, Osamu Masamune, \\ Eietsu Ouchi, Hikaru Watanabe and Yoshio Goto \\ The Third Department of Internal Medicine, Tohoku University \\ School of Medicine, Sendai 980
}

\begin{abstract}
Hrwatashi, N., Kikuchi, T., Masamune, O., Ouchi, E., Watanabe, H. and Goro, Y. HLA Antigens in Inflammatory Bowel Disease. Tohoku J. exp. Med., 1980, 131 (4), 381-385 — HLA antigens were studied in 60 patients with ulcerative colitis, 10 with Crohn's disease and 120 healthy Japanese controls. HLA typing was performed by the microdroplet lymphocyte cytotoxicity test. B5 was recognized in $62 \%$ of the patients with ulcerative colitis, whereas in $40 \%$ of controls $(p<0.01)$. Furthermore, in these patients, B7 was decreased in incidence $(p<0.05)$ and there was the highest relative risk value for $\mathrm{A} 3(R . R .=$ 6.3). When the patients were classified into 2 groups according to the extent of the lesions, left-sided or total colitis group and proctitis group, B5 was recognized in $65 \%$ of the patients with left-sided colitis or total colitis; and this increase was statistically significant. However, no significant difference in the incidence of B5 was recognized between the patients with proctitis and controls, probably because the number of patients studied was too small for evaluation. In the patients with Crohn's disease, B27 was recognized in one patient, showing an increase in incidence $(p<0.001)$, although the number of patients studied was very small. - HLA antigens; ulcerative colitis; Crohn's disease
\end{abstract}

Although the causal factors in inflammatory bowel disease, that is, ulcerative colitis and Crohn's disease, are still unknown, one probable factor is thought to be immunological abnormality. This has led to a considerable number of researches from the viewpoint of abnormalities in the response to infective agents, allergenic reactions to exogenous antigens, an autoimmune response, etc. Ulcerative colitis and Crohn's disease show a high family incidence, indicating the involvement of genetic factors as well. We have undertaken an investigation of these factors from the perspective of the HLA pattern.

\section{SubjeCts and Methods}

Subjects included 60 patients definitively diagnosed as ulcerative colitis (46 with leftsided or total colitis and 14 with proctitis), 10 patients with Crohn's disease, and 120 healthy Japanese as controls. The diagnostic criteria were provided by the Investigation and Research Committee for Ulcerative Colitis (Organized by the Ministry of Health and Welfare in 1973) and the Japanese Research Committee for Crohn's Disease of the Japanese Society of Gastroenterology (1976).

Received for publication, June 22, 1979.

This investigation was partly supported by Grant from the Ministry of Health and Welfare, Japan. 
HLA typing was made by means of the microdroplet lymphocyte cytotoxicity test (Mittal et al. 1968). Anti-sera were obtained from Behring Institute, Bosei Co. and Dr. Juji of the Blood Transfusion Service of Tokyo University. The investigation was made of $8 \mathrm{~A}$ locus and $15 \mathrm{~B}$ locus antigens. From these results the $p$ value was obtained using the $\chi^{2}$ test and the relative risk (R.R.) was calculated.

\section{Results}

B5 was found in $62 \%$ of the cases of ulcerative colitis, that is significantly more frequent $\left(\chi^{2}=7.53, p<0.01\right.$ and $\left.R . R .=2.41\right)$ than $40 \%$ in the control (Table 1 ). B7 was seen in only $7 \%$, that is significantly a few $\left(\chi^{2}=3.95, p<0.05\right.$ and $R . R .=$ 0.34 ) (Table 1). No significant differences in any of the other antigens were seen between ulcerative colitis and control cases, but the highest relative risk for A3 was seen $(R . R .=6.26)$ (Table 1). Considering the extent of the lesion of ulcerative colitis, it was found that $65 \%$ of the left-sided and total colitis patients had B5, which was a significantly high incidence over the control value $\left(\chi^{2}=8.49, p<0.005\right.$ $R . R .=2.81$ ); whereas $50 \%$ of the proctitis patients had B5, the incidence being somewhat lower but not significantly different from the control value (Table 2). With regard to the HLA pattern in the determination of the prognosis in proctitis cases, particularly with regard to the significance of B5, it was seen that only 2 of 4

TABLE 1. Incidence of HLA antigens in patients with inflammatory bowel disease and controls

\begin{tabular}{|c|c|c|c|}
\hline HLA antigens & $\begin{array}{l}\text { Controls } \\
(N=120)\end{array}$ & $\begin{array}{l}\text { Ulcerative colitis } \\
\qquad(N=60)\end{array}$ & $\begin{array}{c}\text { Crohn's disease } \\
\qquad(N=10)\end{array}$ \\
\hline \multicolumn{4}{|l|}{ A loues } \\
\hline A 1 & $1(0.8)$ & 0 & 0 \\
\hline A 2 & $52(43.3)$ & $26(43.3: 1.00)$ & $7(70: 3.05)$ \\
\hline A 3 & $1(0.8)$ & $3(5.0: 6.26)$ & 0 \\
\hline A 9 & $70(58.3)$ & $35(58.3: 1.00)$ & $5(50: 0.71)$ \\
\hline A 10 & $30(25.0)$ & $14(23.3: 0.91)$ & $4(40: 2.00)$ \\
\hline A 11 & $21(17.5)$ & $10(16.7: 0.94)$ & $2(20: 1.18)$ \\
\hline Aw 19 & - & 4/17(23.5:- - ) & - \\
\hline Aw $30 / 31$ & - & $2 / 17(11.8:-)$ & - \\
\hline \multicolumn{4}{|l|}{ B locus } \\
\hline B 5 & $48(40.0)$ & $37(61.7: 2.41) \dagger$ & $4(40: 1.00)$ \\
\hline B 7 & $21(17.5)$ & $4(6.7: 0.34) *$ & $1(10: 0.52)$ \\
\hline B 8 & $3(2.5)$ & 0 & 0 \\
\hline B 12 & $18(15.0)$ & $6(10.0: 0.63)$ & 0 \\
\hline B 13 & 0 & $1(1.7:-)$ & 0 \\
\hline B 14 & $1(0.8)$ & 0 & 0 \\
\hline B 15 & $13(10.8)$ & $9(15.0: 1.45)$ & 0 \\
\hline B, 27 & 0 & 0 & $1(10:-) \ddagger$ \\
\hline $\mathrm{Bw} 17$ & $2(1.7)$ & 0 & 0 \\
\hline Bw 22 & $10(8.3)$ & $5(8.3: 1.00)$ & $1(10: 1.22)$ \\
\hline Bw 35 & $12(10.0)$ & $8(13.3: 1.38)$ & $2(20: 1.80)$ \\
\hline $\mathrm{Bw} 37$ & 0 & 0 & 0 \\
\hline Bw 40 & $42(35.0)$ & $17(28.3: 0.73)$ & $2(20: 0.37)$ \\
\hline Bw 54 & $10(8.3)$ & $2(3.3: 0.38)$ & $1(10: 1.22)$ \\
\hline
\end{tabular}

Percentages (left) and relative risk values (right) are given in the parentheses.

$* p<0.05, \dagger p<0.01, \ddagger p<0.001$. 
TABLE 2. Incidence of $A 3, B 5$ and $B 7$ in patients with ulcerative colitis, classified by the extent of the lesion, the age at onset and sex

\begin{tabular}{|c|c|c|c|c|c|c|c|}
\hline \multirow[b]{2}{*}{$\begin{array}{c}\text { HLA } \\
\text { antigens }\end{array}$} & \multirow[b]{2}{*}{$\begin{array}{c}\text { Controls } \\
(N=120)\end{array}$} & \multicolumn{2}{|c|}{ The extent of the lesion } & \multicolumn{2}{|c|}{ The age at onset } & \multicolumn{2}{|c|}{ Sex } \\
\hline & & $\begin{array}{c}\text { Proctitis } \\
(N=14)\end{array}$ & $\begin{array}{l}\text { Left-sided and } \\
\text { total colitis } \\
(N=46)\end{array}$ & $\begin{array}{c}<30 \\
(N=32)\end{array}$ & $\begin{array}{c}30 \leqq \\
(N=28)\end{array}$ & $\begin{array}{c}\text { Male } \\
(N=29)\end{array}$ & $\begin{array}{c}\text { Female } \\
(N=31)\end{array}$ \\
\hline A3 & $1(0.8)$ & $1(7.1)$ & $2(4.3)$ & $1(3.1)$ & $2(7.1)^{*}$ & 0 & $3(9.7) \dagger$ \\
\hline B5 & $48(40.0)$ & $7(50.9)$ & $30(65.2) \ddagger$ & $20(62.5)^{*}$ & $17(60.7)^{*}$ & $18(62.1)^{*}$ & $19(61.3) *$ \\
\hline $\mathrm{B} 7$ & $21(17.5)$ & 0 & $4(8.7)$ & $3(9.4)$ & $1(3.6)$ & $2(6.9)$ & $2(6.5)$ \\
\hline
\end{tabular}

Percentages are given in the parentheses.

${ }^{*} p<0.05$, $† p<0.01,+p<0.005$.

TaBLE 3. HLA antigens in cases of proctitis developed into left-sided colitis during the observation period

\begin{tabular}{llcccl} 
& Case & Age & Sex & A locus & B locus \\
\hline 1 & G.H. & 37 & F & A9 - & B5 \\
2 & Y.K. & 67 & F & A2 A3 & B12 - \\
3 & O.M. & 33 & F & A9 - & B12 Bw 35 \\
4 & H.K. & 29 & F & A9 & B5 - \\
\hline
\end{tabular}

cases in which proctitis developed into left-sided colitis during the observation period had B5 antigens (Table 3). With regard to the age at onset, by arbitrarily dividing these cases into two groups, younger than 30 years, and 30 years or older, B5 was seen in $63 \%$ and $61 \%$, respectively, both the values were significantly higher than the corresponding value in the control $(p<0.05)$ (Table 2). In the two age-groups, $\mathrm{A} 3$ was found in $3 \%$ and $7 \%$, respectively, only the latter incidence being significantly higher than the control value $(p<0.05)$ (Table 2). With regard to sex, both the male and female cases of ulcerative colitis showed significantly high incidences of B5 $(p<0.05)$, and the female cases showed a significant increase in A3 $\left(\chi^{2}=7.47, p<0.01\right.$ and $\left.R . R .=12.75\right)$ (Table 2). Dividing ulcerative colitis cases according to the extent of the lesion, age at onset and sex, no significant differences in the incidence of B7 were found between them and the controls (Table 2). In brief, B5 was found to be common in left-sided colitis and total colitis, regardless of age at onset or sex, and $A 3$ to be common in females over the age of 30 at onset.

The HLA antigen profile of the Crohn's disease cases did not differ significantly from the controls except one case with regard to B27 $\left(\chi^{2}=12.09, p<0.001\right.$ and corrected $p<0.023$ ) (Table 1 ). This case was a 19 -year-old male who had had the disease, located at the ileum and caecum for 3 years, but no ankylosing spondylitis.

\section{Discussion}

It has been reported that there is no significant correlation between HLA antigens and inflammatory bowel disease in Caucasians (Morris et al. 1974; Russell 
et al. 1975; Bergman et al. 1976; Mallas et al. 1976). With regard to the HLA profile of Japanese cases of ulcerative colitis, Tsuchiya et al. (1977) have reported an increase in B5 and decreases in Aw30/31 and Bw35, whereas Yagita et al. (1977) have reported increases in $A 3, B 5$ and $B w 16$. In the present study, we have found an increase in B5, a decrease in B7 and a high relative risk for A3. These three reports are in agreement only with regard to the increase in B5 as compared with controls. There is also the possibility that B5 or the $\mathrm{D}$ locus, which is linked with B5, is a genetic factor responsible for the susceptibility to ulcerative colitis. Moreover, since a significantly large number of cases of left-sided or total colitis, but not of proctitis, are found to have the B5 antigen, even when the causal factors are the same, it is possible that the inflammation in cases without B5 stops at the proctitis stage. However, only 2 of the 4 cases showing development into leftsided colitis from proctitis had B5 antigens. We therefore intend to study a greater number of cases of proctitis to determine the prognosis of proctitis cases with B5 antigen.

With regard to Crohn's disease, Tsuchiya et al. (1978) studied 10 cases and found a tendency to increases in B5 and A10 and decreases in Aw30/31 and Bw35, whereas in our study an increase in B27 was seen. However, in both studies the number of cases has been too small to allow for final conclusion. Henceforth, it will be necessary to conduct examinations of the HLA profile in Crohn's disease at many institutions.

\section{Acknowledgment}

Thanks are due to Dr. Takeo Juji for supplying the Japanese anti-sera.

\section{References}

1) Bergman, L., Lindglom, J.B., Säfwenberg, J. \& Krause, U. (1976) HL-A frequencies in Crohn's disease and ulcerative colitis. Tissue Antigens, 7, 145-150.

2) Investigation and Research Committee for Ulcerative Colitis (1975) The diagnostic criteria of ulcerative colitis. Jap. med. J., No. 2673, 31-34. (Japanese)

3) Japanese Research Committee for Crohn's Disease of the Japanese Society of Gastroenterology (Chairman: Prof. S. Yamagata) (1976) The diagnostic criteria of Crohn's disease. Jap. J. Gastraent., 73, 1467-1478. (Japanese)

4) Mallas, E.G., Mackintosh, P., Asquith, P. \& Cooke, W.T. (1976) Histocompatibility antigens in inflammatory bowel disease. Their clinical significance and their association with arthropathy with special reference to HLA-B27 (W27). Gut, 17, 906910.

5) Mittal, K.K., Mickey, M.R., Singal, D.P. \& Terasaki, P.I. (1968) Serotyping for homotransplantation. XVIII Refinement of microdroplet lymphocyte cytotoxicity test. Transplantation, 6, 913-927.

6) Morris, R.I., Metzger, A.L., Bluestone, R. \& Terasaki, P.I. (1974) HL-A-W27 - A useful discrimination in the arthropathies of inflammatory bowel disease. New Engl. J. Med., 290, 1117-1119.

7) Russell, A.S., Percy, J.S., Schlaut, J., Sartor, V.E., Goodhart, J.M., Sherbaniuk, R.W. \& Kidd, E.G. (1975) Transplantation antigens in Crohn's disease. Linkage of associated ankylosing spondylitis with HL-Aw27. Dig. Dis., 20, 359-361.

8) Tsuchiya, M., Yoshida, T., Asakura, H., Hibi, T., Ono, A., Mizuno, Y. \& Tsuji, K. (1977) HLA antigens and ulcerative colitis in Japan. Digestion, 15, 286-294. 
9) Tsuchiya, M., Ono, S., Asakura, H., Mizuno, Y. \& Aiso, S. (1978) Major histocompatibility complex in ulcerative colitis and Crohn's disease. Jap. J. clin. Med., 36, 3151-3158. (Japanese)

10) Yagita, A., Abe, O., Baba, S. \& Sekiguchi, S. (1977) HLA typing in patients with colon and rectum cancer, and ulcerative colitis with special reference to cancer susceptibility. Cancer \& Chemotherapy, 4, 939-945. (Japanese) 